\title{
Major Causes of Organ and Carcass Condemnation and Its Financial Losses in Cattle Slaughtered at Wolaita Sodo Municipal Abattior, Snnprs, Ethiopia
}

\author{
Tigabu Korga Jalda Tesfaye Heliso \\ College Of Veterinary Medicine, Haramaya University , Ethiopia
}

\begin{abstract}
A cross sectional study was conducted from November 2017 to April 2018 with the objective of assessing the major causes and rate of organ/carcass condemnation and to estimate annual financial loses in cattle slaughtered at Wolaita Sodo Municipal Abattoir, SNNPR, Ethiopia. From all 368 cattle selected randomly and examined 165 (44.8\%) and $120(32.6 \%)$ showed both ante-mortem and postmortem abnormalities respectively. Conditions like lameness 52(14.1\%), salivation 26(7.1\%), branding 24(6.5\%), diarrhea $20(5.4 \%)$ and rough hair $16(4.3 \%)$, lacrimation $10(2.7 \%)$, local swelling $8(2.2 \%)$ were the major recorded abnormalities in ante-mortem examination. In postmortem examination $65(17.7 \%)$ livers, $41(11.1 \% / 280.8 \mathrm{~kg})$ carcass due to bruise and abscess, $19(5.2 \%)$ lung, $4(1.1 \%)$ hearts and $2(0.5 \%)$ tongues was rejected due to various abnormalities. The major pathological lesions that caused organ condemnations were fasciola $47(12.8 \%)$, bruising $36(9.8 \%)$, calcification $10(2.7 \%)$, hydrated cyst $5(1.3 \%)$, abscessation $5(1.3 \%)$ and cysticercus bovis $5(1.3 \%)$. There was statistically significant association $(p<0.05)$ between liver condemnation and body condition categories of animals. There was no statistical significance $(\mathrm{P}>0.05)$ between the origin and age of animals with the condemnation rate of different organs. The annual financial loss due to the rejection of organs and carcass of cattle slaughtered at Wolaita Sodo municipal abattoir was estimated approximately 148,643 ETB (5,505.3USD). This huge financial loss indicates that there should be appropriate disease prevention and control program in the study area.
\end{abstract}

Keywords: Abattoir, Ante-mortem, Financial loss, Organ condemnation, Post-mortem

DOI: $10.7176 / \mathrm{JHMN} / 74-04$

Publication date:May $31^{\text {st }} 2020$

\section{INTRODUCTION}

The world human population is growing at faster rate than food production and this increase occurs mainly in developing countries with the rate of $2.4 \%$ per year (UN, 2017). Developing countries have nearly $2 / 3$ (two third) of the world's livestock population, but produce less than a third of the world's meat and fifth of its milk (FAO, 1995). According to recent estimates, Ethiopia has 59.5 million cattle, 30.7 million sheep, 30.20 million goats, 1.21 million camels, 2.16 million horse, 8.44 million donkey, 0.41 million mule and 56.53 million poultry (CSA, 2016/17). The livestock subsector currently support and sustain livelihoods for $80 \%$ of all rural population in Ethiopia and the sector contributes to 12 and $33 \%$ of the total and agricultural GDP, respectively, and accounts for $12-15 \%$ of total export earnings (Alemu et al., 2017). The GDP of livestock related activities valued at birr 59 billion (Metaferia et al., 2011) but according to Berhanu (2006), Africa in general and Ethiopia in particular, the level of ruminant livestock production doesn't commensurate with its size.

Most studies conducted in different abattoirs of Ethiopia proved that parasitic diseases were major problems that cause organ and carcass condemnation that caused great economic loss (Jember, 2002; Assefa and Tesfaye, 2013; Agegn et al., 2016). The main reason arise with this increase were the in efficient management practice, low veterinary services, poor quality feed and extensive husbandry system. Meat in the slaughter house is condemned in order to break down the chain of zoonosis that are not directly transmitted by meat like hydatidosis, for aesthetic values caused by disease and mechanical damage at the slaughter house (Dejene et al., 2013).

Abattoir data can be a source of valuable information on the incidence and epidemiology of animal disease conditions, to estimate the financial losses incurred through condemnation of affected organs (Arbabi and Hooshyr, 2006; Raji et al., 2012). On the other hand surveillance at the abattoir allows for all animals passing into human food chain to be examined for unusual signs, lesions or specific diseases (Alton et al., 2010). Abattoir is one of the site from which zoonosis can arise; So Meat inspection can help to know to what extent the public is exposed to certain zoonotic diseases (Raji et al., 2012; Singla and Juyal, 2014). It is mandatory to have clear information on causes of organ and carcass condemnation and to locate and manage the site on which the pathological lesions occur and to analyze financial loss (Yimam, M. (2003); Aseffa, (2005)).

Meat is a nutritious food that has an important role in balanced human diet and the primary aim of the abattoir is to produce healthy meat, wholesome and clean products which are safe for human consumption (Cadmus and Adesokan, 2009). Meat inspection at abattoirs, for hygienic quality, involves both ante mortem and postmortem examination which include gross and microbiological investigation (Aissi et al., 2013).

There are both ante-mortem and postmortem abnormalities that cause organ and carcass condemnation of 
beef in the world general and Ethiopia in particular. The main reported cause of whole carcass condemnation in Ethiopia were: Poor bleeding, Abscess, Adhesion, TB, Pneumonia, Cysticercus bovis, Bruising and Hydatid cyst while carcasses bruising, poor bleeding, contamination and adhesion were main causes of partial condemnations (Mummed and Webb, 2015).

Most of the abattoir studies were undertaken on prevalence of fasciolosis and hydatidosis and the extent of loss from organs condemnation in different parts of Ethiopia (Bekele and Butako, 2011; Tembo and Nonga, 2015; Wabe et al., 2017). Thus, there is limited information on other causes of organ and carcass condemnation in the country, particularly in the study area.

Therefore, this study was conducted with the objective of:

$>$ Investigating the major causes of organ/carcass condemnation at Wolaita Sodo municipal abattoir.

$>$ Estimating the rate of organ/carcass condemnations based on potential risk factors

$>$ Estimating annual financial losses due to organ/carcass condemnation in the study area.

\section{MATERIALS AND METHODS}

\subsection{Study Area}

The study was conducted from November 2017 to April 2018 at Wolaita Sodo municipal abattoir. Wolaita zone is located in SNNPRS and is situated $390 \mathrm{~km}$ south of Addis Ababa. The altitude ranges from the lowest at the foot of Omo river valley 501 MASL to highest 2,950 MASL at peak of Mount Damota and geographically located between $6^{\circ} 36^{\prime} \mathrm{N}$ to $7^{\circ} 18^{\prime} \mathrm{N}$ latitude and $3712^{\prime} \mathrm{E}$ up to $3824^{\prime} \mathrm{E}$ longitude. It experiences an average annual rain fall ranging from 450 to $1,446 \mathrm{~mm}$. The rainfall over much of the areas is typically bimodal with the major rainy season extending from June to September and the short rainy season occurring from February to April. The mean annual maximum and minimum temperature of the area is 34.1 and $11.4^{\circ} \mathrm{C}$, respectively. The main economic source in the area is mixed farming system and the area has moderately drained acidic red soils (nitosols). The livestock population of Wolaita zone is estimated to be 886,242 bovines, 117,274 ovine, 99,817 caprine, 41,603 equines and 442,428 poultry (SNNPRSAB, 2007).

\subsection{Study Population}

The study animals included in present study were mainly male animals that came from the surrounding zone/districts of Wolaita zone (Dawro, Arsinegele, Arba-Minch, Humbo, and Areka). Animals of different breeds, age, sex, and body condition were included. The age of the animal was estimated on the basis of the dentitions (De Lahunta and Habel, 1986) and conventionally grouped into two; adult ( $<6$ years) and old ( $\geq 6$ years).The body condition score was given by according to the rule of (Nicholson and Butterworth, 1986). Based on this animals were categorized as good, medium and poor body conditioned. Animals which score $(2,3$ were categorized as poor/lean); (4, 5, 6, were medium) and ( 7 was classified as good/fat) but there was no any animal that score one.

\subsection{Sample Size Determination}

The numbers of cattle included in this study were calculated based on the formula given by Thrusfield, (2005) at the 39.68\% expected prevalence of organ rejection in the study area by Abunna and Hordofa (2013), with 5\% desired precision and 95\% confidence interval. Therefore, a sample size of 368 cattle was included in this study

and the number was obtained based on the following calculation: $n=\frac{1.96^{2} * p_{\exp }\left(1-p_{\exp }\right)}{d^{2}}$

When: $\mathrm{n}=$ required sample size; Pexp= expected prevalence; $\mathrm{d}=$ desired absolute precision.

\subsection{Study Design and period}

The study was conducted based on active abattoir survey and a cross-sectional study was conducted from November 2017 to April 2018 to assess the main causes and rate of organ and carcass condemnation, to estimate the direct financial loss attributed to condemned organ and carcass. All animals were subjected to the standard ante-mortem and postmortem examination procedures as indicated in manual on meat inspection procedures for developing countries (FAO, 1994). Animals for examination were selected using simple random sampling method by a lottery system based on the number given on ante-mortem examination.

\subsection{Ante-mortem Inspection}

Ante-mortem inspection was conducted and the animals were given with the identification number on their back. Animals were checked for any deviation from their normal behaviors, illness, posture and gait, and conditions of mucus membranes (Gracey, J., 1986). 


\subsection{Postmortem Examination}

Postmortem examination of all organs was made based on routine meat inspection procedures (inspection, palpation and systematic incision) and different abnormalities such as, bruising, Fasciola, hydatid cyst, Cysticercus bovis, emphysema, pneumonia and others were appreciated in the respective organs (liver, lung, kidney, tongue, and heart). Judgments were given according to the meat inspection manual for developing countries (FAO, 1994).

\subsection{Assessment of Direct Financial Loss}

All affected organs and carcasses were subjected to partial condemnation or totally condemned to reduce the public health problem and to enhance the market demand. The analysis was made based on annual slaughter per annum organ and carcass condemnation rate and the current average price of each organ and a weight of carcass in Wolaita Sodo town. Accordingly, average market price was determined by interviewing personnel of about ten butcher's houses found in the town. Finally, the financial loss was calculated based the formula set by EDO et al. (2014) for the estimation of annual economic loss of bovine visceral organs in Adama municipal abattoir.

$$
\begin{aligned}
& \mathrm{L}=(\mathrm{Ni} \times \mathrm{Pj}) \\
& \text { Where, } \\
& \mathrm{L}=\text { total loss, } \\
& \mathrm{Ni}=\text { Number of visceral organs condemned annually and } \\
& \mathrm{Pj}=\text { Average price of visceral organs. }
\end{aligned}
$$

The financial loss associated with carcass condemnation due to bruising and abscess was calculated based on the annual rate of the carcass rejection expressed in kilogram and price of one kilogram of bovine meat in the local market. In the study each treamed carcass was taken as averagely one third of a kilogram $(1$ tream $=1 / 3 \mathrm{~kg}$ estimation). Based on this, the annual economic loss of carcass condemnation was computed as follows:

$$
\begin{aligned}
& \mathrm{L}=(\mathrm{Ci} \times \mathrm{Pj}) \\
& \text { Where, } \mathrm{Ci}=\text { kilograms of carcass rejected annually, } \\
& \quad \mathrm{Pj}=\text { average price of one kilogram meat. }
\end{aligned}
$$

\subsection{Data Management and Analysis}

The data obtained in both ante-mortem inspection and postmortem examination was entered in a Microsoft Excel spreadsheet and analyzed using Statistical Package for Social Sciences version 20. The prevalence of causes for organ and carcass condemnation was determined as a proportion of affected animals out of the total animal are examined. The association between different risk factors such as animal origin, age, and body condition with disease condition were analyzed by using $\chi^{2}$ (Chi-square) technique and value of $\mathrm{p}<0.05$ was considered as significant.

\section{RESULTS}

\subsection{Ante-mortem Findings}

Out of the total 368 animals examined $165(44.8 \%$ ) were found with different abnormalities (Table 1). Lameness $52(14.1 \%)$, salivation $26(7.1 \%)$, diarrhea $20(5.4 \%)$, branding $24(6.5 \%)$, rough hair $16(4.3 \%)$, lacrimation $10(2.7 \%)$, local swelling $8(2.2 \%)$, depression and tick each, $3(0.8 \%)$, tattooing $2(0.5 \%)$ and weakness $1(0.3 \%)$ were the major ante-mortem abnormalities recorded respectively.

Table 4: Summary of abnormal conditions encountered during ante-mortem examination

$$
\text { Condition encountered Frequency (\%) of }
$$

\begin{tabular}{ll}
\hline Branding & $24(6.5)$ \\
Depression & $3(0.8)$ \\
Diarrhea & $20(5.4)$ \\
Lacrimation & $10(2.7)$ \\
Lameness & $52(14.1)$ \\
Rough hair & $16(4.3)$ \\
Salivation & $26(7.1)$ \\
Swelling & $8(2.2)$ \\
Tattooing & $2(0.5)$ \\
Ticks & $3(0.8)$ \\
Weakness & $1(0.3)$ \\
Overall & $165(44.8)$ \\
\hline
\end{tabular}

$\mathrm{n}=368$ (total animals examined)

\subsection{Overall Carcass and Organ Condemnation}

The overall organ and carcass rejection rate was 120(32.6\%). From these condemned organ and carcass, 63(17.1\%) 
were totally condemned, while $57(15.5 \%)$ were partially condemned (Table 2 ). The overall condemnation rate of organs and carcass was highest in poor body conditioned animals $10(45.5 \%)$, than medium and good body condition scored animals which were 53(32.3\%) and 57(31.3\%), respectively. The condemnation of carcass was only partial one.

Table 5: Overall carcass/organ rejection rate

\begin{tabular}{|c|c|c|c|c|}
\hline \multirow{2}{*}{$\begin{array}{l}\text { Variable } \\
\text { categories }\end{array}$} & \multirow{2}{*}{$\begin{array}{l}\text { Total number of } \\
\text { cattle slaughtered }\end{array}$} & \multicolumn{3}{|c|}{ Judgment given } \\
\hline & & $\begin{array}{l}\text { Partial } \\
\text { condemnation }\end{array}$ & $\begin{array}{l}\text { Total } \\
\text { condemnation }\end{array}$ & $\begin{array}{l}\text { Overall } \\
\text { condemnation }\end{array}$ \\
\hline \multicolumn{5}{|l|}{ Age } \\
\hline Adult & 157 & $27(17.2 \%)$ & $26(16.6 \%)$ & $53(33.7 \%)$ \\
\hline Old & 211 & $30(14.2 \%)$ & $37(17.5 \%)$ & $67(31.7 \%)$ \\
\hline Total & 368 & $57(15.5 \%)$ & $63(17.1 \%)$ & $120(32.6 \%)$ \\
\hline \multicolumn{5}{|l|}{ Body condition } \\
\hline Good & 182 & $22(12.1 \%)$ & $35(19.2 \%)$ & $57(31.3 \%)$ \\
\hline Medium & 164 & $31(18.9 \%)$ & $22(13.4 \%)$ & $53(32.3 \%)$ \\
\hline Poor & 22 & $4(18.2 \%)$ & $6(27.3 \%)$ & $10(45.5 \%)$ \\
\hline Total & 368 & $57(15.5 \%)$ & $63(17.1 \%)$ & $120(32.6 \%)$ \\
\hline \multicolumn{5}{|l|}{ Origin } \\
\hline Arbaminch & 1 & $0(0.0 \%)$ & $1(100.0 \%)$ & $1(100.0 \%)$ \\
\hline Areka & 46 & $8(17.4 \%)$ & $6(13.0 \%)$ & $14(30.4 \%)$ \\
\hline Arsinegele & 13 & $1(7.7 \%)$ & $2(15.4 \%)$ & $3(23.1 \%)$ \\
\hline Dawro & 37 & $5(13.5 \%)$ & $7(18.9 \%)$ & $12(32.4 \%)$ \\
\hline Gasuba & 61 & $11(18.0 \%)$ & $7(11.5 \%)$ & $18(29.5 \%)$ \\
\hline Humbo & 210 & $32(15.2 \%)$ & $40(19.0 \%)$ & $72(34.3 \%)$ \\
\hline Total & 368 & $57(15.5 \%)$ & $63(17.1 \%)$ & $120(32.6 \%)$ \\
\hline \multicolumn{5}{|l|}{ Breed } \\
\hline Local & 352 & $54(15.3 \%)$ & $60(17.0 \%)$ & $114(32.4 \%)$ \\
\hline Cross & 15 & $3(20.0 \%)$ & $2(13.3 \%)$ & $5(33.3 \%)$ \\
\hline Exotic & 1 & $0(0.0 \%)$ & $1(100.0 \%)$ & 1 \\
\hline Total & 368 & $57(15.5 \%)$ & $63(17.1 \%)$ & $120(32.6 \%)$ \\
\hline
\end{tabular}

\subsection{Major Causes of Organ and Carcass Condemnation}

As indicated in Table 3, out of the total organs and carcass examined 131(35.6\%) were found with different abnormalities. The frequency was high in liver $(17.7 \%)$ and carcass $(11.1 \%)$. Among all causes, mechanical damage and parasitic diseases were the dominant problems that resulted in high rate of organ/carcass condemnation. Fasciola was ranked highest $47(12.8 \%)$ as a cause of liver condemnation followed by calcification $10(2.7 \%)$, hydatid cyst and abscess each 3(0.8\%) and hemorrhage 2(0.5\%). Out of the rejected carcass, majority $(9.8 \%)$ was due to bruising.

Table 6: Type of abnormality encountered and role in organ and carcass rejection

\begin{tabular}{|c|c|c|c|c|c|c|}
\hline \multirow{2}{*}{$\begin{array}{l}\text { Type of } \\
\text { abnormality }\end{array}$} & \multicolumn{5}{|c|}{ Frequency $(\%)$ in } & \multirow[t]{2}{*}{ Total } \\
\hline & Heart & Liver & Lung & Carcass & Tongue & \\
\hline Abscess & - & $3(0.8)$ & - & $2(0.5)$ & - & $5(1.3)$ \\
\hline Bruising & & - & - & $36(9.8)$ & & $36(9.8)$ \\
\hline C. bovis & $\overline{3}(0.8)$ & & - & - & $\overline{2}(0.5)$ & $5(1.3)$ \\
\hline Calcification & - & $\overline{10} 0(2.7)$ & - & - & - & $10(2.7)$ \\
\hline Color change & - & - & & - & - & \\
\hline CBPP & - & - & $\overline{4}(1.1)$ & - & - & $\overline{4}(1.1)$ \\
\hline Emphysema & - & & $4(1.1)$ & - & - & $4(1.1)$ \\
\hline Fasciola & - & $\overline{4} 7(12.8)$ & & - & - & $47(12.8)$ \\
\hline Hydatid cyst & & $3(0.8)$ & $\overline{2}(0.5)$ & & - & $5(1.1)$ \\
\hline Hemorrhage & $\overline{1}(0.3)$ & $2(0.5)$ & $1(0.3)$ & $\overline{3}(0.8)$ & - & $7(1.9)$ \\
\hline Pneumonia & & & $8(2.1)$ & & & $8(2.1)$ \\
\hline Total rejection* & $4(1.1)$ & $65(17.7)$ & $19(5.2)$ & $41(11.1)$ & $2(0.5)$ & 131(35.6) \\
\hline
\end{tabular}

\subsection{Condemnation Rates in Relation with Risk Factors}

As indicated in Table 4, the rate of liver condemnation was similar between adult $(17.8 \%)$ and old aged animals (17.5\%). Similarly, there was little difference in the lung condemned between adult (5.7\%) and old (4.7\%). There was no statistically significant difference in the frequency of liver and lung condemnation with the age categories 
of the animals $(\mathrm{p}>0.05)$ but there was statistically significant association between liver condemnation with body condition of cattle slaughtered in the abattoir $(p<0.05)$.

Table 7: Rejection rates of liver and lung based on age categories and body condition score

\begin{tabular}{|c|c|c|c|c|c|}
\hline \multirow[b]{2}{*}{ Variable } & \multirow[b]{2}{*}{ Categories } & \multicolumn{2}{|c|}{ Liver } & \multicolumn{2}{|c|}{ Lung } \\
\hline & & Positive (\%) & $\begin{array}{c}\chi^{2} \\
\text { (p-value) }\end{array}$ & Positive (\%) & $\begin{array}{c}\chi^{2} \\
\text { (p-value) }\end{array}$ \\
\hline Age & $\begin{array}{l}\text { Adult }(\mathrm{n}=157) \\
\text { Old }(\mathrm{n}=211) \\
\text { Total }\end{array}$ & $\begin{array}{l}28(17.8) \\
37(17.5) \\
\mathbf{6 5}(17.7) \\
\end{array}$ & $\begin{array}{l}0.006 \\
(0.941)\end{array}$ & $\begin{array}{l}9(5.7) \\
10(4.7) \\
\mathbf{1 9}(5.2) \\
\end{array}$ & $\begin{array}{l}0.181 \\
(0.670)\end{array}$ \\
\hline $\begin{array}{l}\text { Body } \\
\text { condition }\end{array}$ & $\begin{array}{l}\text { Good }(n=182) \\
\text { Medium }(n=164) \\
\text { Poor }(n=22) \\
\text { Total }\end{array}$ & $\begin{array}{l}30(16.5) \\
26(15.9) \\
9(40.9) \\
\mathbf{6 5}(\mathbf{1 7 . 7})\end{array}$ & $\begin{array}{l}8.718 \\
(0.013)\end{array}$ & $\begin{array}{l}12(6.6) \\
6(3.7) \\
1(4.5) \\
19(5.2)\end{array}$ & $\begin{array}{l}1.536 \\
(0.464)\end{array}$ \\
\hline
\end{tabular}

$\mathrm{n}=$ total animals examined

\subsection{Estimation of Financial Loss}

Based on annual slaughter rate of 5040 cattle, the estimated annual financial loss associated to organ and carcass condemned in Wolaita Sodo Municipal Abattoir was 148,643 ETB/ (5,505.3 USD) (Table 7). The average price of each organ and one kilo meat was assessed from the butcher's and as 30, 100, 20, 200, and 5birr for heart, liver, tongue, one kilogram meat and lung respectively. Higher financial losses recorded with liver condemnation $(89,000 \mathrm{ETB})$ and carcass condemnation $(56,160 \mathrm{ETB})$ (Table 7). The financial loss had been increasing in the area when compared with the previous research of Abunna and Hordofa, (2013) who reported the annual financial loss as 24,340 ETB.

Table 5: Summary of annual financial loss due to organ and carcass condemnation.

\begin{tabular}{llll}
\hline Organ/carcass & $\begin{array}{l}\text { Average rejection rate of } \\
\text { organs and carcass }\end{array}$ & $\begin{array}{l}\text { Average Price } \\
(\mathrm{ETB})\end{array}$ & Economic loss in ETB \\
\hline Lung & 260 & 5 & 1,300 \\
Liver & 890 & 100 & 89,000 \\
Heart & 54 & 30 & 1643 \\
Carcass (meat) & $280.8 \mathrm{~kg}$ & $200 \mathrm{birr} / \mathrm{kg}$ & 56,160 \\
Tongue & 27 & 20 & 540 \\
Overall & & & $148,643 \mathrm{ETB}$ \\
\hline
\end{tabular}

Note: Current price: $1 \mathrm{USD}=27 \mathrm{ETB}$

\section{DISCUSSION}

Out of 368 cattle subjected to the pre-slaughter inspection at the study period, $165(44.8 \%)$ showed different abnormalities. This record on the ante-mortem abnormalities in the abattoir indicates that the improper handling and poor management practice and lack of awareness on animal's welfare by the area and abattoir. When compared with different research findings, it was so much greater than the reports by Assefa and Tesfaye (2013), (15.3\%), Jatenie et al. (2014) (1.9\%), Moje et al. (2014) (23.47\%), Tefera et al. (2016) (10.68\%), Hussen et al. (2017) (2.9\%). But it was agreed with the report by Agegn et al. (2016) who reported as 38.54\% from Bahir-Dar municipal abattoir. The most encountered ante-mortem abnormalities were lameness 52(14.1\%), salivation 26(7.1\%), branding $26(6.5 \%)$, diarrhea $20(5.4 \%)$, rough hair $16(4.3 \%)$, lacrimation $10(2.7 \%)$, local swelling $8(2.2 \%)$, depression $3(0.8 \%)$, ticks $3(0.8 \%)$, tattooing $2(0.5 \%)$ and weakness $1(0.3 \%)$. These were previously reported by various authors (Regassa et al. (2013); Efrem et al. (2015); Alemu et al. (2017)) form the country.

Out of 368 cattle examined 120(32.6\%) animals were found with at least one type of abnormalities in different organs and/carcass. This finding is lower than reported by Melese et al. (2012) (60.9\%), Moje et al. (2014) (62.8\%), Agegn et al. (2016) (83.6\%), Tesfaye et al. (2017) (71.4\%), and from different districts of the country. This low rate of organ and carcass condemnation may be due to the difference of season on which the research was done, variation in the agro ecologies of the study area and etc. As the present study showed, the most predominant abnormalities encountered in postmortem examination were bruising and faciolosis (parasitic and mechanical damages). These were similar with the findings reported by various authors (Melese et al., 2012; Hussen et al., 2017).

From the total examined animals, 65(17.7\%) of liver were condemned due to different abnormalities. Similarly, Assefa and Tesfaye (2013), Abunna and Hordofa (2013) and Abunna et al. (2010) reported rejection rates of $17.58 \%, 16.64 \%$ and $14 \%$ respectively. Among the causes, fasciola, calcification, haydatid cyst, abscess and hemorrhage were responsible for rejection of $12.8 \%, 2.7 \%, 0.8 \%, 0.8 \%$ and $0.5 \%$ livers respectively. In relation with the previous studies in Wolaita and other abattoirs, the present study report of liver condemnation 
was lower than the reports by Melese et al. (2012) (34.23\%), Abunna and Hordofa (2013) (39.68\%), Moje et al. (2014) (41.75\%) and Maseresha et al. (2016) (44.5\%). The differences in prevalence of liver rejection in different area of Ethiopia could be related with the agro-ecology and the strategic use of veterinary service in the control and prevention of animal disease. Additionally, the people's awareness in the control and prevention of the disease and the management systems difference in different areas.

The overall carcass condemnation was $11.1 \%$. From these, partially for bruising $(9.8 \%)$, abscess $(0.5 \%)$, hemorrhage (0.8\%). The result of current study was greater than the work done by Moje et al. (2014) 29(6.7\%) and Agegn et al. (2016) (7.6\%). The result of study showed that carcass condemnation was the second most important challenge in Wolaita Sodoa battoir and it was mainly due to bruising. The reason for the high prevalence of bruising could be due to the problem animals face during driving by stick from irresponsible individuals who brought the animals, the inappropriate transportation vehicle and the sever challenge that occurs in the lairage through fighting. The stunning condition also resulted in bruise in different animals when they fall down on the concrete ground being unconscious. As reported by Ezana (2008), bruising of animals during transport is the major source of economic loss in Africa and Asia.

The overall condemnation rate of lung was $5.2 \%$ and this was comparable to the work of Moje et al. (2014) that reported a prevalence of $7.16 \%$ from Nekemte Municipality Abattoir. The lung was condemned due to hydatid cyst $(0.5 \%)$, pneumonia $(2.1 \%)$, emphysema $(1.1 \%)$, hemorrhage $(0.3 \%)$, Abscessation $3(0.8 \%)$ and CBPP $(1.1 \%)$. The prevalence of hydatid cyst was lower than reported by Bekele \& Butako, (2011) at Wolaita Sodo municipal abattoir who reported the prevalence of $16.85 \%$, where as it was low as compared to the reports by Debas and Ibrahim, (2013) from north Gonder with the prevalence of $28 \%$. But the current study was in agreement to Assefa and Tesfaye, (2013), that reported emphysema (1.61\%), pneumonia (1.07\%), abscessation $(0.40 \%)$.

The difference in prevalence of lung condemnation at different study area may be due to the prevalence of disease, disease transmitting vector, awareness among people about zoonotic disease, manner of disposal of condemned organs in abattoirs, backyard animal slaughter system and the difference in animal management system.

In current study the heart was condemned due to hemorrhage $1(0.3 \%)$ and Cystcercus bovis $3(0.8 \%)$. There were similar reports were found by Assefa and Tesfaye (2013) from Adigrat Municipal Abattoir with Cysticercus bovis $(0.43 \%)$ and EDO et al. (2014) from Adama Municipal Abattoir, with $0.9 \%$ of Cysticercus bovis. The overall prevalence of heart condemnation was $1.1 \%$ and it was lower than the condemnation rate reported from Dessie Municipal Abattoir by Tefere et al. (2016) who reported as $4.43 \%$ and Shegaw et al. (2009) who reported $3.71 \%$ from Mekele Municipal Abattoir.

In present study the condemnation of tongue was very low and it accounted only $0.5 \%$ due to Cysticercus bovis. This prevalence was in agreement to the work of Shegaw et al. (2009) and Tefere et al. (2016), who reported as $0.78 \%$ and $0.9 \%$ respectively.

\section{CONCLUSION AND RECOMMENDATION}

As recorded in the results of the present study, the overall organ and/carcass rejection rate was quite high (32.6\%). Fasciolosis, bruising, calcification, hydatid cyst, pneumonia and bruise were the most abnormalities that resulted in organ and carcass condemnation. Liver, lung, carcass, heart and tongue were the major organs affected with different abnormalities. The rate of liver condemnation was higher in animals with poor body condition. Laboratory analysis indicated that, majority of fertile hydatid cysts were viable. The study revealed that, there was high amount of economic loss due to organ and carcass condemnation in Wolaita Sodo Municipal Abattoir. Based on the above conclusion the following recommendations are forwarded:

$>$ The transportation system of animals to the abattoir should have to be improved and the drivers should have to take a care during driving,

$>$ The condemned organs should be incinerated,

$>$ The abattoir compound should be fenced and maintained,

$>$ Abattoirs have to be supplied with ample water supply and waste disposal systems have to be given special attention by the abattoir personnel,

$>$ Further study should be done in the area to avoid this huge economic loss.

\section{REFERENCES}

Abunna, F., Asfaw, L., Megersa, B. and Regassa, A. (2010). Bovine fasciolosis: coprological, abattoir survey and its economic impact due to liver condemnation at Soddo municipal abattoir, Southern Ethiopia. Trop. Anim. Health Prod. 42:289-292.

Abunna, F. and Hordofa, D. (2013). Major Causes of Organ Condemnation for Cattle and its Financial Impact at Wolaita Sodo Municipality Abattoir, Southern Ethiopia. Global Vet.11 (6): 730-734.

Agegn, M., Tegegne, B. and Tibebu, S. (2016). Major Causes of Organ and Carcass Condemnation in Cattle and Sheep Slaughtered at Bahir-Dar Municipal Abattoir, Amhara Regional State, Ethiopia. Adv. Bio. Res. 10 (5): 323-334 
Aissi, M., Harhoura, K.H. and Khouni, F. (2013). Prevalence and study of the bovine sarcocystis species in the slaughterhouses of Rouiba (Algiers). J. Veterinar. Sci. Techno. 4(1).

Alemu, A., Deneke, Y. and Ibrahim, N. (2017). Major causes of organ condemnation and its financial loss in cattle in Gondar ELFORA abattoir, Ethiopia. Res. 9(10):31-38

Alton, G.D., Pearl, D.L., Bateman, K.G., McNab, W.B. and Berke, O. (2010). Factors associated with whole carcass condemnation rates in provincially-inspected abattoirs in Ontario 2001-2007: implications for food animal syndromic surveillance. BMC Vet. Res. 6(1): 42.

Arbabi, M.O.H.S.E.N. and Hooshyar, H. (2006). Survey of Echinococcosis and hydatidosis in Kashan region, central Iran. Iran J. Public Health, 35(1): 75-81.

Aseffa, M. (2005). Parasitic causes of carcass/organ condemnation at Asella municipality Abattoir. DebreZeit: Faculty of veterinary Medicine, Addis Ababa University, DVM Thesis.

Assefa, A. and Tesfay, H. (2013). Major causes of organ condemnation and economic loss in cattle slaughtered at Adigrat municipal abattoir, northern Ethiopia. Her. (11): 1-48.

Bekele, J. and Butako, B. (2011). Occurrence and financial loss assessment of cystic echinococcosis (hydatidosis) in cattle slaughtered at WolayitaSodo municipal abattoir, Southern Ethiopia. Trop. Anim. Health prod. 43(1): 221-228.

Berhanu, M. (2006). Major causes of organ condemnationcattle and sheep slaughter in Addis Ababa Abattoirs Enterprise (Doctor of Veterinary Medicine Thesis). Faculty of Veterinary Medicine, Addis Ababa University, DebreZeit.

Cadmus, S. and Adesokan, H. (2009). Causes and implication of bovine organs/offal condemnations in abattoirs in western Nigeria. Trop. Anim. Health Prod. 41(7): 1455-1463.

Center for statistic agency (CSA), (2016/17). Agricultural Sample Survey. Report on livestock and livestock characteristics (private peasant holdings). Central

Statistical Agency (CSA). Addis Ababa.

Debas, E. and Ibrahim, N. (2013). Prevalence and economic importance of hydatidosis in cattle slaughtered at North GonderElfora abattoir. Euro. J. Appl. Sci. 5(1): 29-35.

Dejene, S. Abebe, B. and Degefu, H. (2013). Study on the Major Health Problems That Causes Carcass and Organs Condemnation at Hashim's Export Abattoir, Debrezeit, Ethiopia. Global Vet. 11(4): 362-371.

DeLahunta, A., Habel, R.E. (1986). Teeth. Applied Veterinary Anatomy. WB Saunders Company, USA.

EDO, J.J., PAL, M. and RAHMAN, M.T. (2014). Investigation into major causes of organs condemnation in bovine slaughtered at Adama municipal abattoir and their economic importance. Her. 2: 0-05.

Efrem, L., Serda, B., Sibhat, B. and Hirpa, E. (2015). Causes of organ condemnation, its public health and financial significance in Nekemte municipal abattoir, Wollega, Western Ethiopia. J. Vet. Med. Anim. Health, 7(6): 205214.

Ezana, G.W. (2008). Major diseases of export oriented livestock in export abattoirs in/around Ada LibenWereda, Debre-Zeit (Doctoral dissertation, Haramaya University).

FAO, (1994). Meat inspection manual for developing countries, Rome, Italy.

FAO, (1995). Manual of meat inspection for developing countries. FAO. Anim. Prod. health.

Gracey, J., (1986). Meat Hygiene, 8th ed. London: BaillereTindall. London Philadelphia. Toronto, 239-289.

Hobbs, R.P., Lymbery, A.J. and Thompson, R.C.A. (1990). Rostellar hook morphology of Echinococcus granulosus (Batsch, 1786) from natural and experimental Australian hosts, and its implications for strain recognition. Par. 101(2): 273-281.

Hussen, M., Hussen, S., Chali, G. and Abdurahaman, M. (2017). Parasitic Cause of Organ and Carcass Condemnation in Small Ruminant Slaughtered at Helmex Abattoir, Debre-Zeit, Ethiopia. Int. J. Res. Stud. Biosci. (IJRSB). 5(4): 22-30

Jatenie, J., Mahendra, P. and Rahman, T. (2014). Investigation into major causes of organs condemnation in bovine slaughtered at Adama municipal abattoir and their economic importance. Haryana. Vet. 53:139-143

Jember, S. (2002). A study on causes of organ and carcass condemnation in slaughtered cattle at Nazareth abattoir. DVM thesis Addis Ababa University, Faculty of Veterinary Medicine, DebreZeit, Ethiopia.

Maseresha, S. B, Shibbiru, T. M, and Tadesse, F. W., (2016). Major causes of organ condemnation and associated financial loss in cattle slaughtered at Hawassa Municipal Abattoir, Ethiopia. J.Vet. Med. Anim. Health. 8(10): $150-156$

Melese, G., Guadu, T., Bogale, B. and Chanie, M. (2012). Pathological conditions causing organ and carcass condemnation and their financial losses in cattle slaughtered in Gondar, Northwest Ethiopia. African. J. Basic Appl. Sci. 4: 200-208.

Metaferia, F., T. Cherenet, A. Gelan, F. Abnet, A. Tesfay and W. Gulilat, (2011). A Review to Improve Estimation of Livestock Contribution to the National GDP. Ministry of Finance and Economic Development and Ministry of Agriculture. Addia Ababa, Ethiopia.

Moje, N., Abdeta, D., Kebede, S., Terfa, T.,Desissa, F. and Regassa, A. (2014). Major Causes of Organs and Carcass Condemnation in Cattle Slaughtered at Nekemte Municipality Abattoir, East Wollega, Ethiopia. 
Global Vet. 13(3): 278-284.

Mummed, Y.Y. and Webb, E.C. (2015). Causes of beef carcass and organ condemnations in Ethiopia. Asia J. Anim. Vet. Adv. 10(4): 147-160.

Nicholson, M.J. and Butterworth, M.H. (1986). A guiding to body condition scoring of zebu cattle. International livestock center for Africa, Addis Ababa, Ethiopia.

Raji, M.A., Salami, S.O. and Ameh, J.A. (2012). Pathological conditions and lesions observed in slaughtered cattle in Zaria abattoir. J. Clin. Patho. Foren. Med. 1(2): 9-12.

Regassa, A., Moje, N., Megersaa, B., Beyene, D., Sheferaw, D., Debela, D., Abunnaa, F., Skjerved, E (2013): Major causes of organs and carcass condemnation in small ruminants slaughtered at Luna Export Abattoir, Oromia Regional State, Ethiopia. Preventive Veterinary Medicine 110: 139- 148.

Shegaw, S., Ashwani, K. and Kassaw, A. (2009). Organs condemnation and economic loss at Mekelle municipal abattoir, Ethiopia. Har. Vet. 48:17-22.

Singla LD. andJuyal PD. (2014). Sarcocystosis. In: Zoonosis: Parasitic and Mycotic Diseases, Garg SR (Ed), Daya Publishing House, New Delhi, 235-250.

SNNPRSAB, 2007. South nation nationalities people regional state agricultural bureau.

Tefera, Y., Mesfin, Z. and Muleta, W. (2016). Major causes and abnormalities of organ condemnation and financial loss in cattle slaughtered at Dessie municipal abattior North Eastern Ethiopia. J. Vet. Med. Anim. Health, 8(7): 56-63.

Tembo, W. and Nonga, H.E. (2015). A survey of the causes of cattle organs and/or carcass condemnation, financial losses and magnitude of foetal wastage at an abattoir in Dodoma, Tanzania. Onderstepoort J. Vet. Res. 82(1): 01-07.

Tesfaye, W., Mekonnen, T. and Areru, A. (2017). Major causes of organ condemnation and financial significance in cattle slaughtered at Jimma Municipal Abattoir, Southwestern Ethiopia. Int J Adv. Res Biol. Sci. 4(2):32391

Thrusfield, M. (2005). Veterinary epidemiology, government department of Navy, Bureau 2ed UK Black well science Ltd., 182-198.

UN. (2017). The World Population Prospects: The 2017 Revision, published by the UN Department of Economic and Social Affairs.

Wabe, N., Abraha, A. and Alemu, S. (2017). Parasitic and Gross Pathological Causes of Cattle Organ and Carcass Condemnation at Hawassa Municipal Abattoir, Ethiopia. Adv. Biol. Res. 11 (6): 373-381.

Yimam, M. (2003). Major causes of organ condemnation in ruminants slaughtered at Gondar abattoir, Northwest Ethiopia. DVM thesis, Addis Ababa University, Faculty of Veterinary Medicine, Debre-Zeit, Ethiopia. 
Photo taken from Liver and Lung which was infested by Hydatid Cyst Hydatid cyst in the liver
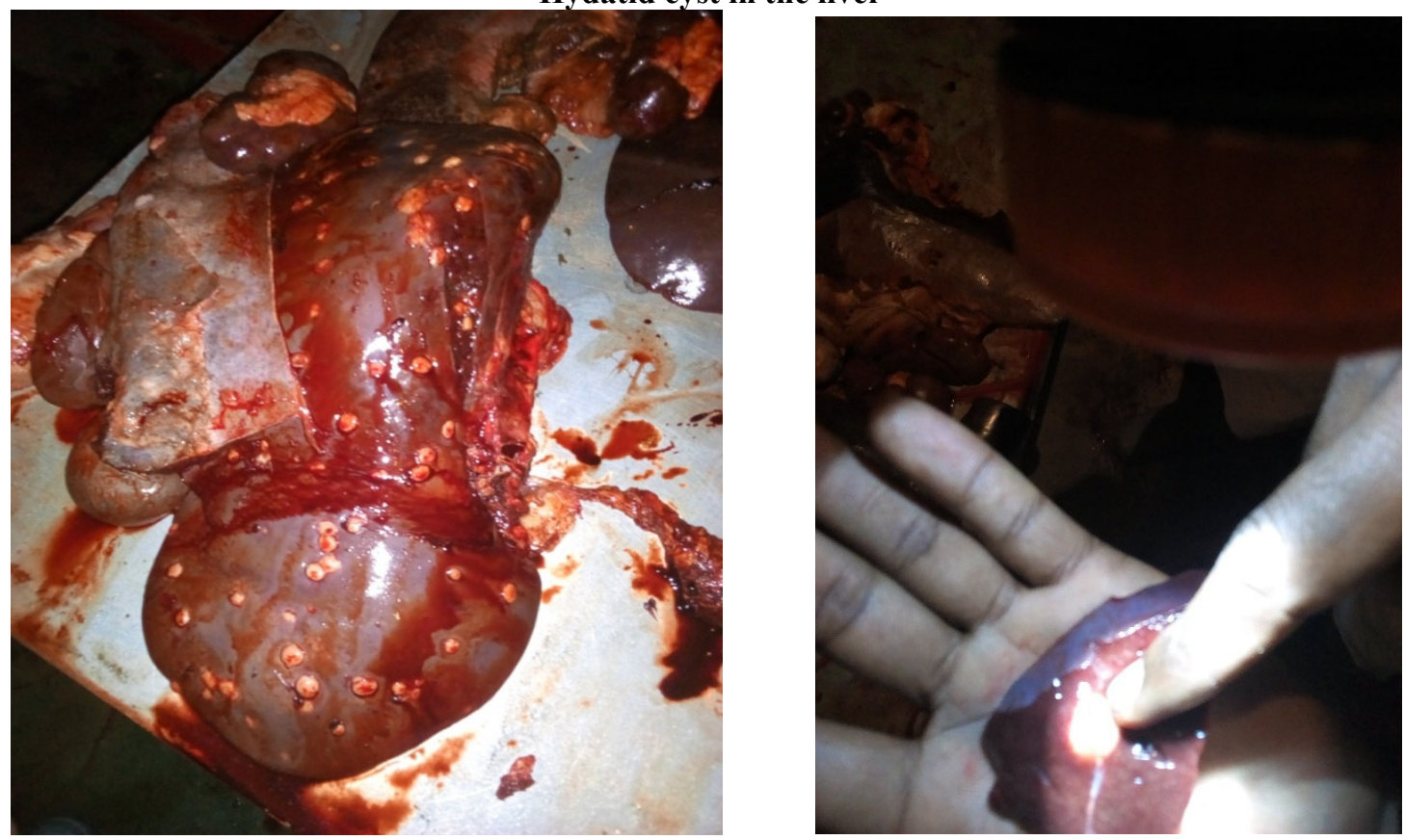

\section{Hydatid cyst in lung}
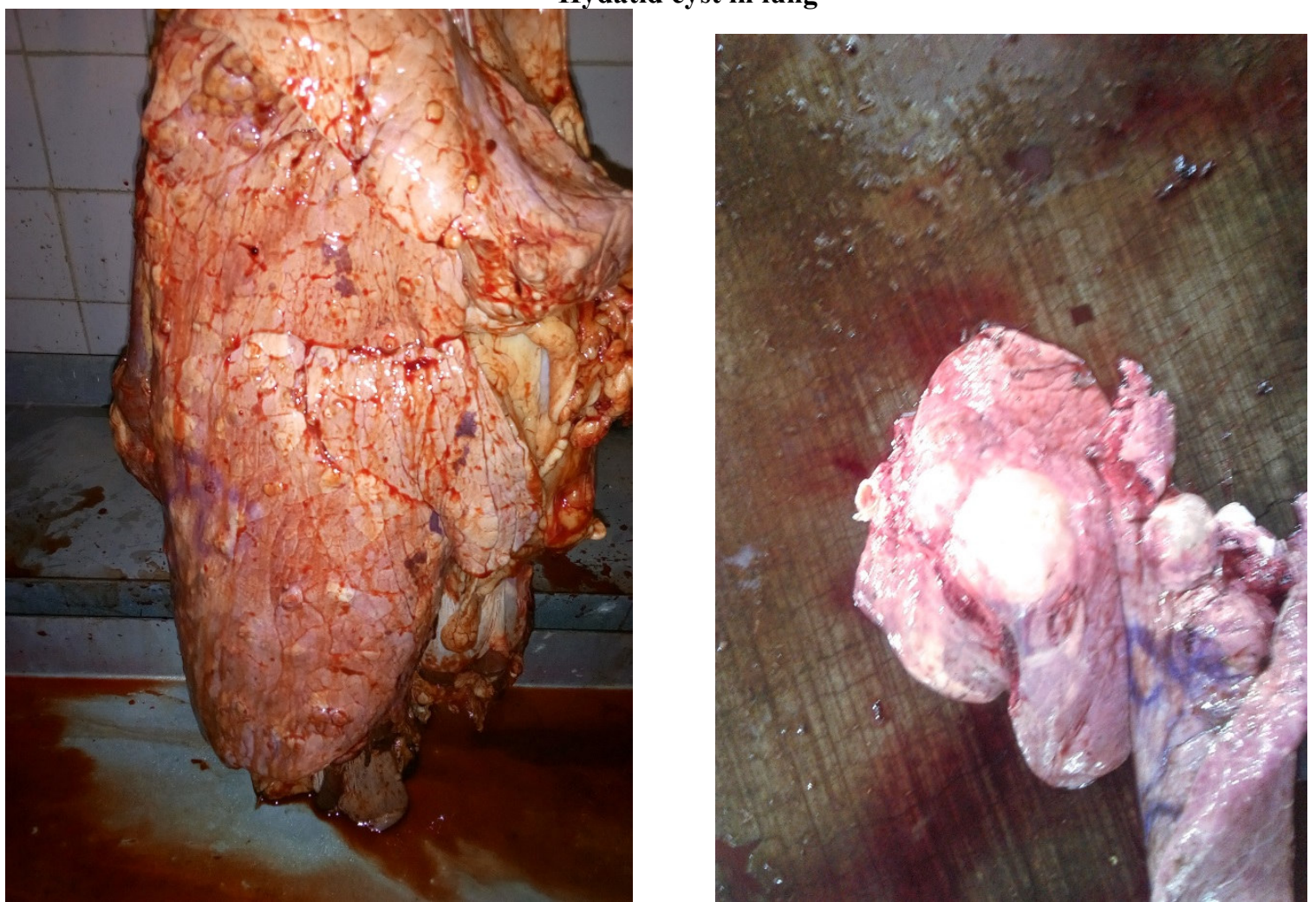

(Source $=$ Wolaita Sodo abattoir, by Tesfaye and Tigabu 2018) 